\title{
$\mathrm{AZ31}$ 합금 판재의 온간 점진 성형에 관한 연구
}

\author{
김상우\#. 이영선 ${ }^{1} \cdot$ 권용남 $^{1} \cdot$ 이정환 $^{1}$
}

\section{A Study on Warm Incremental Forming of AZ31 Alloy Sheet}

\author{
S. W. Kim, Y. S. Lee, Y. N. Kwon, J. H. Lee
}

(Received July 7, 2008)

\begin{abstract}
A fundamental study on warm incremental forming of a magnesium alloy sheet has been carried out. In order to enhance the incremental formability of the magnesium alloy sheet, a local heating device was newly designed and manufactured. Through the incremental forming tests of AZ31 under various forming conditions, the effects of process parameters such as the temperature, feeding depth per cycle, and inclination angle on the incremental formability of AZ31 were investigated. In addition, conventional FLDs at elevated temperatures were constructed experimentally and applied to predict the forming failure.
\end{abstract}

Key Words : Incremental Forming, Magnesium, Warm Forming, FLD, FEM, Formability

\section{1. 서 론}

최근 다품종 소량생산 제품에 대한 산업적 수 요가 증가하면서 점진 퐌재 성형기술에 대한 관 심이 높아지고 있다. 점진 판재 성형기술은 별도 의 상-하 금형 없이 하나의 공구가 계산된 경로 에 따라 이동하면서 삼차원 형상을 점진적으로 성형해 나가는 방법으로 자동차 및 항공기 부품 의 시제품 개발, 맞춤형 의로기기 등에 적용함으 로써 초기 제품개발기간 축소, 제조비용 절감 등 의 이점이 있다. 그 동안 많은 선행연구자들에 의 해 점진 판재 성형기술에 대한 연구가 진행되어 왔는데 점진 판재 성형에서의 변형해석[1 2], 성형 성[3 5], 공구경로생성 기법[6]에 관한 연구가 주 류를 이루었다. 이들 연구는 주로 연강, 알루미늄 과 같이 상온 성형성이 비교적 양호한 소재에 국 한되어 진행되어 왔다.

자동차, 항공기 등 수송기기류의 경량화 추세에

1. 한혹기계연구월 부설 재료연구소

\# 게신저자: 한국기계연구원 부설 재로연구소,

E-mail: kimsw@kims.re.kr
힘입어 최근 마그네숨과 같은 경량소재에 대한 관심이 높아지고 있다. 마그네슘은 경량성, 우수 한 절삭성, 전자파 차폐성 등 다양한 이점으로 인 해 산업적 수요가 늘어가고 있으나, 육방정계 결 정구조로 인해 상온 성형성이 열악함예 따라 온 간 성형에 대한 연구가 집중적으로 이루어 지고 있다.

본 연구에서는 앞서 말한 점진 판재 성형공정 및 마그네슴 합금의 장점을 활용하여 산업적 적 용범위를 확대하기 위한 초기단계로 온간 점진 판재 성형에 관한 기초연구를 수행하였다. 마그네 숨 합금 판재의 성형성을 향상하기 위한 방안으 로 점진 퐌재 셩형장비에 독자적으로 제작된 국 부 가열장치를 장착하여 성형온도, 1 회 성형깊이, 기울임 각 등 다양한 성형조건에서의 실험을 통 하여 이들 공정변수가 AZ31 마그네슘 합금 판재의 점진 성형성에 미치는 영향을 분석하였다. 또한, 유 한요소빕과 AZ31 소재의 성형한계선도(FLD)를 
이용하여 성형한계를 예측함으로써 기존의 성형 한계선도를 이용한 네킹 및 파단 발생 판단 가능 여부를 검토하였다.

\section{AZ31 합금 파재의 기계적 물성}

두께 $0.8 \mathrm{~mm}$ 인 AZ31 마그네습 합금 퐌재의 고 온에서의 기계적 물성을 측정하기 위하여 100 , $200,300,400^{\circ} \mathrm{C}$ 의 네 가지 온도 및 변형률 속도 $0.01,0.1,1 / \mathrm{s}$ 에서의 인장시험을 수행하였다. 실험은 압연방향에 대하여 $0^{\circ}, 45^{\circ}, 90^{\circ}$ 의 세 방향으로 시 편을 절단하여 방향별로 수행하였으며, 식(1)의 평 균유동응력으로 근사하여 분석한 결과를 Fig. 1, 2 에 나타내었다.

$$
\bar{\sigma}=\left(\sigma_{0}+2 \sigma_{45}+\sigma_{90}\right) / 4
$$

진 응력은 온도가 증가함에 따라 감소하는 반 면 변형률 속도가 증가함에 따라 증가하는 경향 을 보였으며, 전 연신률은 온도가 증가함에 따라 증가하는 반면 변형률 속도가 중가함에 따라 감 소하는 경항으로 보였다. 특히, $400^{\circ} \mathrm{C}$ 에서 변형률 속도 $0.01 / \mathrm{s}$ 의 경우 급격한 연신률 증가를 보였 다.

\section{3. 온간 점진 판재 성형용 가열장치}

상온에서의 성형성이 열악한 마그네슘 합금의 성형성을 향상시키고, 점진 성형 공정에 적용하 기 위하여 점진 성형용 국부 가열장치를 설계하 였다. 가열장치의 설계에 있어서 다음의 세가지 설계인자가 고려되었다. 첫째, 3 차원으로 이동하 는 공구의 이동경로를 방해하지 않을 것. 둘째, 가열로 인한 공정시간 종대를 최소화하기 위해 급속가열이 가능할 것. 셋째, 변형영역내의 온도 제어가 가능할 것. 상기의 세 가지 설계인자를 고려하여, Fig. 3 과 같이 할로겐 램프를 이용한 국 부가열 장치의 설계 및 제작을 완료하였다. 가열 장치는 공구에 장착되어 공구와 함께 이동함으 로써 이동경로에 방해를 받지 않으며, 여섯 개의 'U'자형 할로겐램프를 사용하여 급속가열을 가능 하게 하였다. 또한, 변형영역내의 온도제어를 위 해 열전대가 소재에 접촉할 수 있도록 설치하고, 이를 통해 온도를 제어할 수 있도록 시스템을 구현하였다.
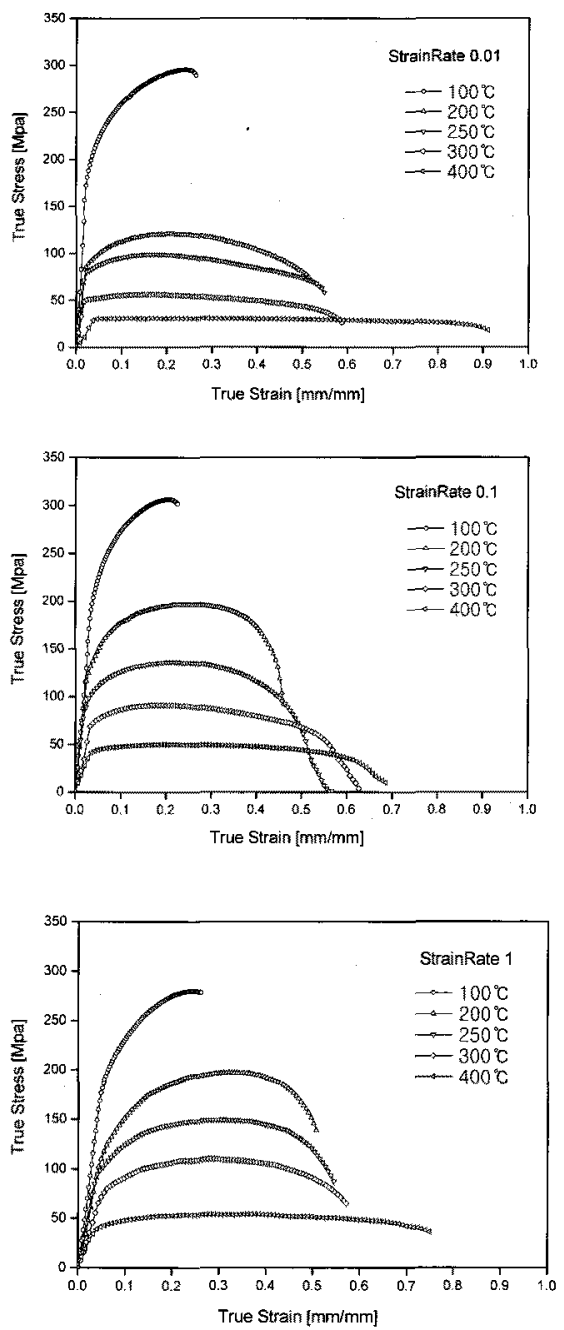

Fig. 1 Flow stresses at various temperatures and strain rates

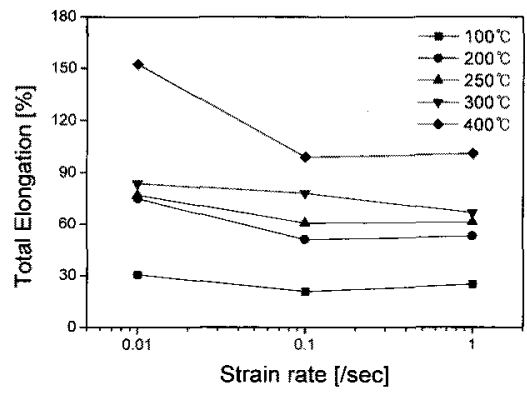

Fig. 2 Total elongations at various strain rates and temperatures 


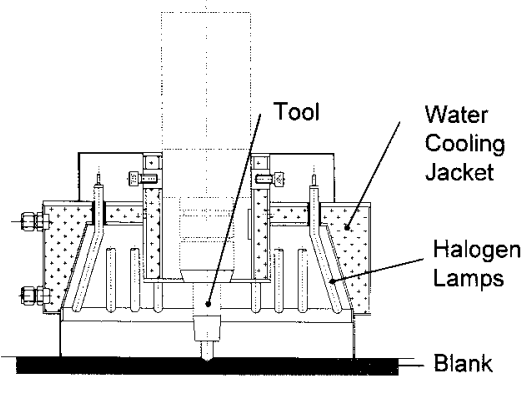

Fig. 3 Schematic of heating device

\section{4. 공정변수의 영향}

마그네슴합금의 온간 점진 성형에서의 공정변수 들의 영향을 살펴보기 위해 두 가지 기본형상의 모 델을 Fig. 4와 같이 선정하여, 국부 가열장치를 이용 한 온간 점진 성형실험을 수행하였다. 실험모델은 직경(가로변) $100 \mathrm{~mm}$, 높이 $50 \mathrm{~mm}$ 의 높이에 따라 단 면이 줄어드는 사각기둥 및 원기둥 형상의 두 개 모델을 선정하였다. 성형공구는 직경 $10 \mathrm{~mm}$ 의 반구 형을 사용하였으며, 자연발화점이 $400^{\circ} \mathrm{C}$ 인 합성오 일을 윤활제로 사용하였다. 공구의 속도는 초기 예 비가열을 위해 $10 \mathrm{~mm} / \mathrm{s}$ 으로 수 회 성형한 후, $100 \mathrm{~mm} / \mathrm{s}$ 까지 점진적으로 속도를 증가시킴으로써 일정온도가 유지될 수 있도록 하였다. 실험은 1 회 전 당 성형깊이, 성형온도, 모델의 기울임 각을 달 리하여, 다양한 공정변수에 대한 영향을 검토할 수 있도록 하였다. Fig. 5 는 국부 가열장치를 장착한 점 진 성형 공정 장비를 보여주고 있다.

\subsection{1 회 성형깊이에 대한 영향}

우선, 1 회 성형깊이에 따른 성형성을 조사하기 위하여 성형온도 $250^{\circ} \mathrm{C}$, 기울임 각 $45^{\circ}$ 인 조건하 에서 1 희 성형깊이를 $0.2 \mathrm{~mm}, 3 \mathrm{~mm}$ 로 달리하여 실 험을 수행하였다. 그 결과 Fig. 6에서 보이는 것과 같이 두 가지 모델 모두 1회 성형깊이가 작을수 록 성형가능 높이가 커지는 것으로 나타났으며, 원형 모델의 경우 파단까지의 성형깊이가 사각형 모델보다 큰 것으로 나타났다. 이는 사각형 모델 의 평행부에서의 평면변형에 의한 성형한계의 감 소로 판단된다.

\section{2 성형온도의 영향}

둘째로, 성형온도의 영향을 살펴보기 위하여 100 ,

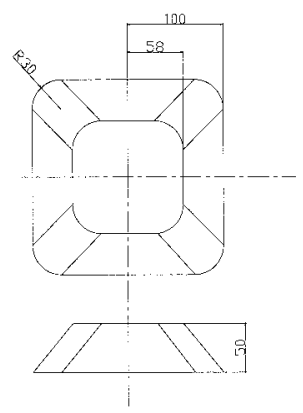

(a) Model A

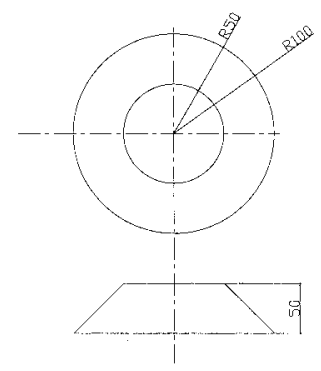

(b) Model B
Fig. 4 Two types of test model

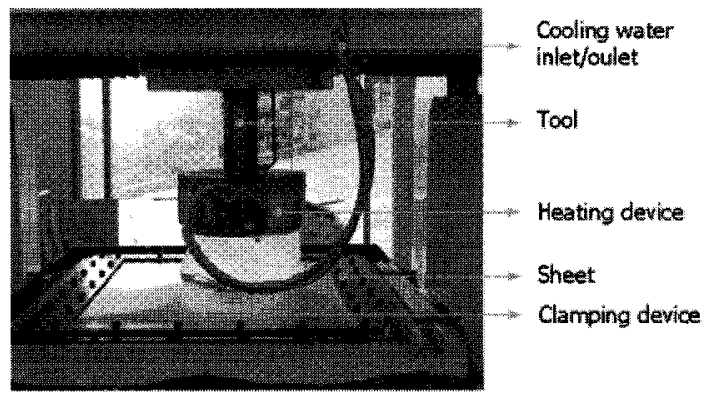

Fig. 5 Incremental forming at elevated temperatures

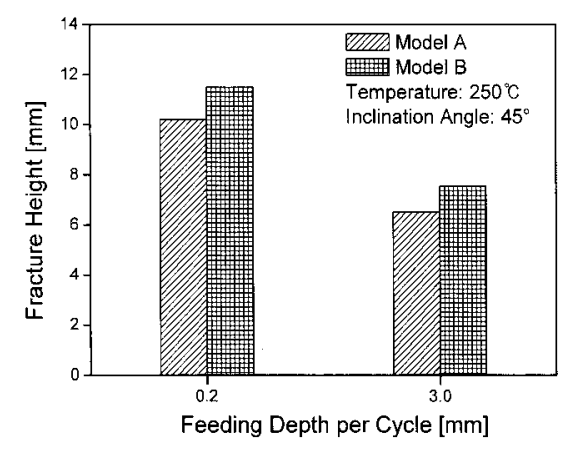

Fig. 6 Effect of process parameters: Feeding depth

$200,250,300^{\circ} \mathrm{C}$ 의 온도에서 1 회 성형깊이를 $0.2 \mathrm{~mm}$, 기울임 각 $45^{\circ}$ 의 동일한 조건에서 실험을 수행한 결과를 Fig. 7에 나타내었다. 성형온도가 증가함에 따라 파단높이도 증가하는 경향을 보였으며, $200{ }^{\circ} \mathrm{C}$ 이상에서는 급격한 성형성 증가를 나타내 었다. 또한, 원형모델이 사각형모델에 비해 성형 이 잘 되는 것으로 나타났다. 


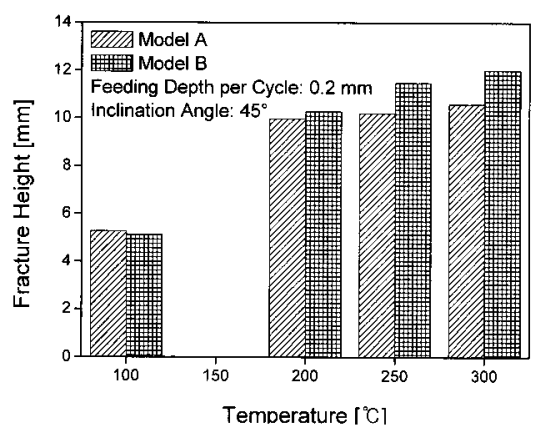

Fig. 7 Effect of process parameters: Forming temperature

\section{3 기울임 각에 대한 영향}

판재의 점진 성형 공정은 국부적인 변형을 유 도하여 전체적인 형상을 점진적으로 성형하는 공 정으로 Table 1 의 좌측 그림과 같이 변형영역내부 의 소재 체적은 일정하므로 기울임 각이 콜수록 두께가 앏아지게 된다. 따라서, 기울임 각은 점진 성형의 성패를 좌우하는 주요한 설계변수로 작용 한다. 본 연구에서는 기울임 각이 성형성에 미치 는 영향을 분석하기 위하여 $30^{\circ}, 35^{\circ}, 40^{\circ} 45^{\circ}$ 의 네 가지 경우에 대한 실험을 수행하였다. 성형온도 및 1 회 성형깊이는 앞서 수행된 실험에서 가장 성형결과가 좋았던 $250^{\circ} \mathrm{C}, 0.2 \mathrm{~mm}$ 로 고정하고, 두 가지 모델에 대한 실험을 수행하였다. 실험결과, Table 1에서와 같이 온도 및 1 회 성형깊이가 동일 한 조건하에서 기울임 각이 $35^{\circ}$ 이상일 경우, 두 모델 모두 높이 $50 \mathrm{~mm}$ 가 도달하기 전 파단이 발 생하였다. 따라서, 상기 조건하에서의 마그네숩 합금의 점진 성형을 위한 최소 기울임 각은 $30^{\circ}$ 부근인 것으로 판단된다. Fig. 8, 9는 실험결과 파단 이 발생한 경우와 성공적으로 성형이 이루어진 경우를 보여주고 있다.

\section{5. 성형한계선도 구축}

온간 점진 성형 공정에서의 성형한계를 예측하 기 위하여 성형한계선도(FLD)가 고려되었다. Fig. 10 과 같이 $\Phi 100$ 반구형 금형에 카트리지 히터를 삽입하여 가열하였으며, 변형경로를 다양하게 하 기 위해 각각 폭이 다른 시편을 제작하여 100 , $200,250,300^{\circ} \mathrm{C}$ 의 네 가지 온도조건에서 실험을 수행하였다. 본 연구에서는 점진 판재 성형에서의 주 변형모드인 평면변형 및 2축 인장 모드에서의
Table 1 Effect of inclination angle on formability

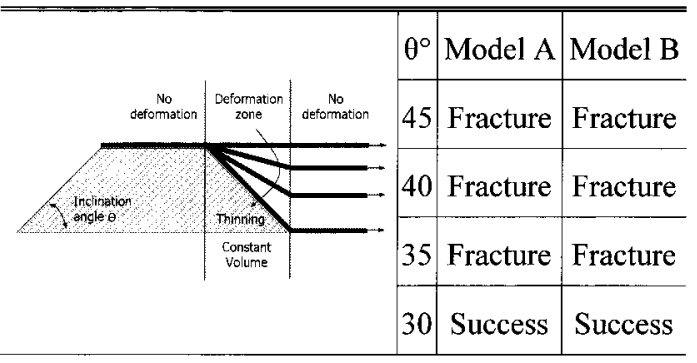

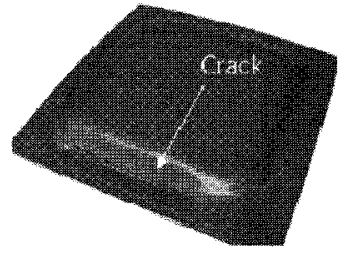

(a) Model A

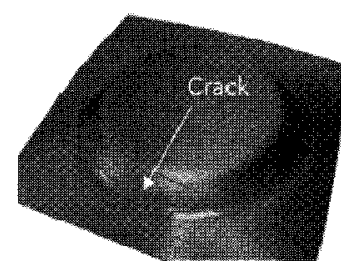

(b) Model B
Fig. 8 Experimental results: crack occurrence $(T=$ $250^{\circ} \mathrm{C}$, Inclination angle $=45^{\circ}$ )

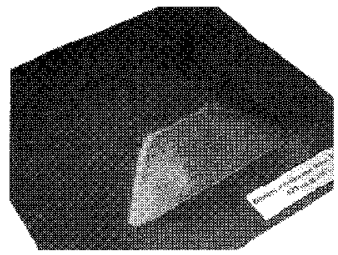

(a) Model A

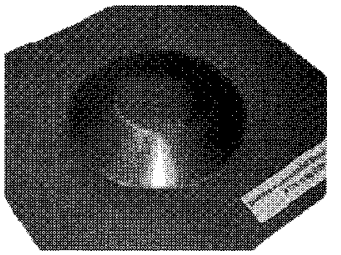

(b) Model B
Fig. 9 Experimental results: successful forming ( $T=$ $250^{\circ} \mathrm{C}$, Inclination angle $=30^{\circ}$ )
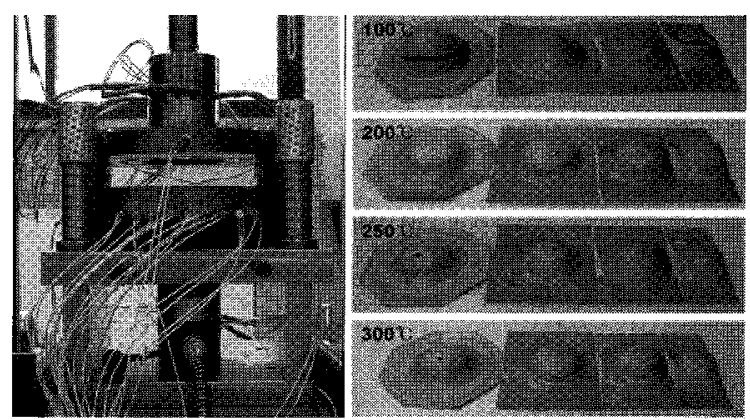

Fig.10 Tool set and specimens for FLD test

성형한계선도만 고려되었으며, 그 결과는 Fig. 11 과 같이 온도가 증가함에 따라 한계변형률 역시 중가하는 경향을 보였다. 


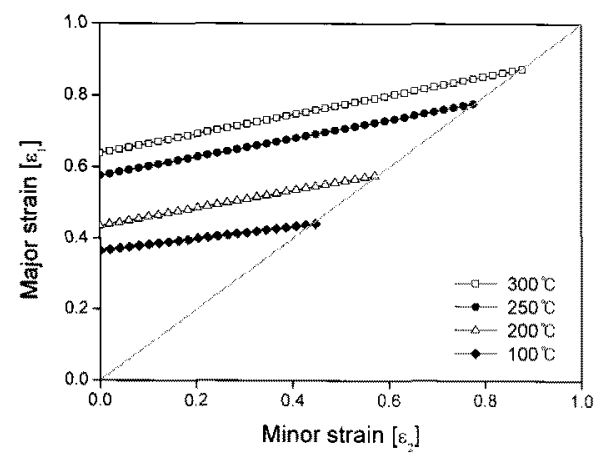

Fig.11 FLCs at various temperatures

\section{6. 유한요소 성형해석}

온간 점진 성형 공정에서의 소성변형해석 및 성형한계선도를 이용한 성형한계예측을 위하여 상용 유한요소해석 코드인 ABAQUS-Explicit 을 이용한 공정해석을 수행하였다. Fig. 12 와 같이 공 구, 상하 홀더, 베이스 몰드는 강체로 가정되었으 며, 소재는 변형률 속도를 고려한 탄소성체로 가 정하였다. 공정 중에는 변형영역내의 균일한 가열 이 이루어졌다는 가정하에 $250^{\circ} \mathrm{C}$ 의 등온공정으로 해석하였다.

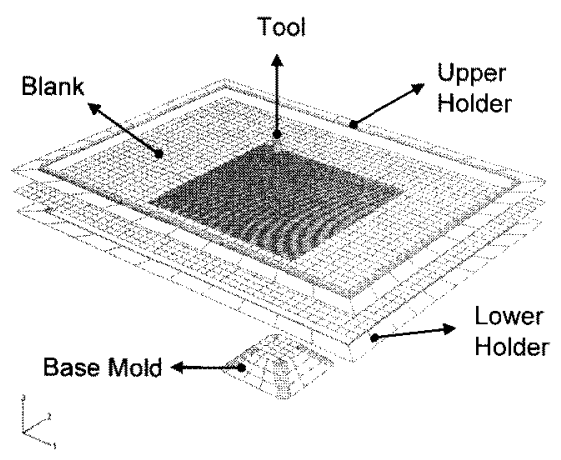

Fig. 12 Finite Element Model

\section{1 변형률 분포}

앞서 수행된 실험에서 파단이 발생하였던 성형 온도 $250^{\circ} \mathrm{C}$, 기울임 각 $45^{\circ}$ 인 경우와 파단이 발생 하지 않고 높이 $50 \mathrm{~mm}$ 까지 성형된 경우의 각각의 모델에 대한 유한요소해석이 수행되었다. Fig. 13은 파단이 발생한 경우의 해석결과 최대 변형률 분 포를 보여주고 있는데 두 가지 모델 모두 평면변

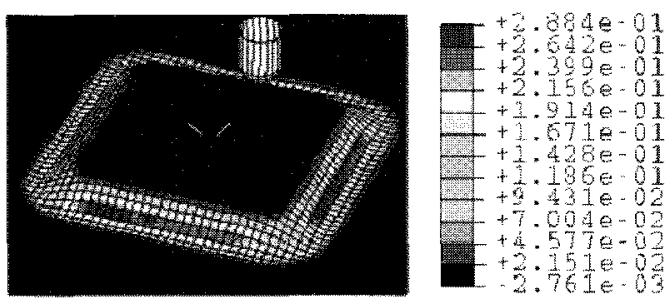

(a) Model A

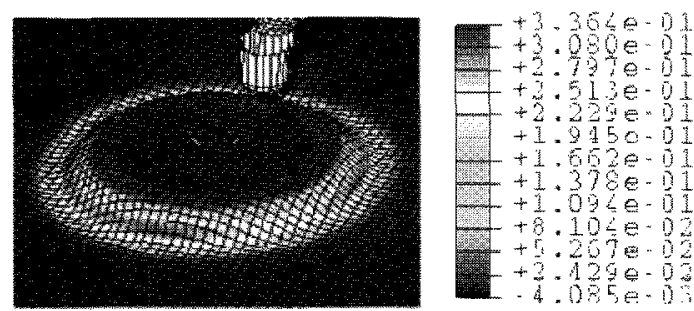

(b) Model B

Fig.13 FE analysis: crack occurrence $\left(T=250^{\circ}\right.$, Feeding depth per cycle $=0.2 \mathrm{~mm}$, Inclination angle $=\mathbf{4 5}^{\circ}$ )
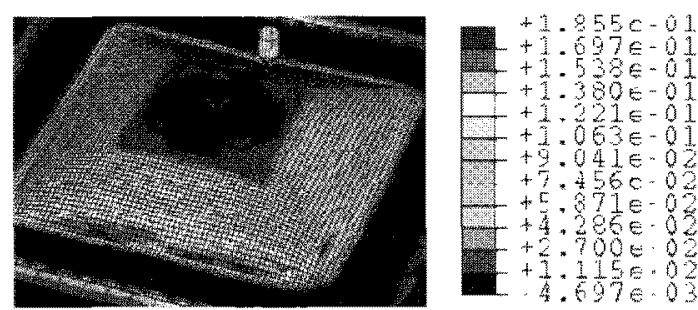

(a) Model A
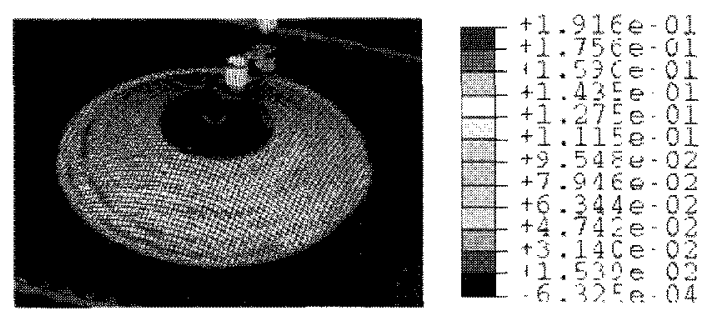

(b) Model B

Fig. 14 FE analysis: no crack ( $T=250 \mathrm{C}$, Feeding depth per cycle $=0.2 \mathrm{~mm}$, Inclination angle $=30^{\circ}$ )

형이 작용하는 평행부에서 최대 인장 변형률이 발생하였다. Fig. 14는 높이 $50 \mathrm{~mm}$ 까지 성형이 완료 된 경우의 해석결과로 사각형 모델의 경우 최대 인장 변형률이 0.186 으로 파단이 된 경우의 0.288 에 비해 $35 \%$ 가량 작게 나타났으며, 원형 모델의 경우 0.192 로 곽단된 경우의 0.336 에 비해 $43 \%$ 가 량 작게 나타났다. 


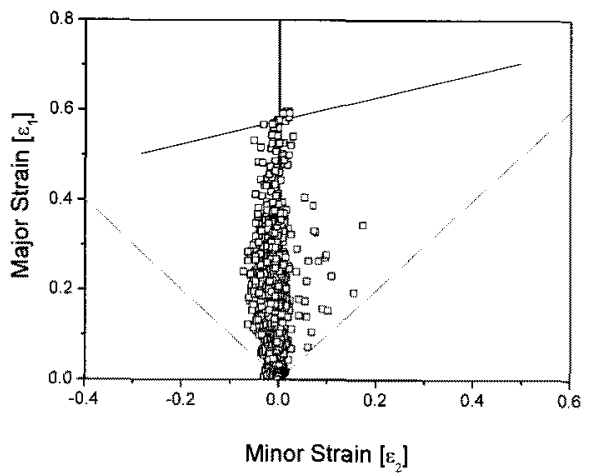

(a) Model A

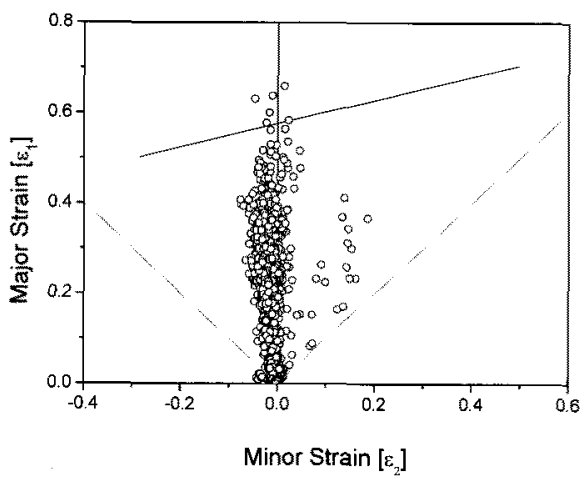

(b) Model B

Fig. 15 Failure prediction: no $\operatorname{crack}\left(T=250^{\circ} \mathrm{C}\right.$, Feeding depth per cycle $=0.2 \mathrm{~mm}$, Inclination angle $=30^{\circ}$ )

\section{2 성형한계선도를 이용한 파단예측}

실험을 통해 도출된 성형한계선도와 해석결과 를 이용하여 마그네슘 합금의 온간 판재 점진 성 형공정에서의 파단을 예측해 보았다. 그 결과, Fig. 15 에서와 같이 마단이 된 경우에는 두 모델 모두 주변형률이 평면 변형상태에서 한계변형률을 초 과함으로써 실험과 동일하게 파단올 예측하였으 며, Fig. 16의 파단이 되지 않은 경우에는 각 요소 의 변형률이 한계변형률 아래에 분포됨으로써 파 단없이 성형이 완료될 수 있음을 예측하였다.

\section{7. 결 론}

본 연구에서는 마그네숨 합금 퐌재의 온간 점 진 성형을 위하여 국부 가열장치를 이용하여 기 초실험을 수행함으로써 공정변수의 영향을 분석 하였으며, 파단을 예측하기 위하여 고온에서의 성 형한계선도를 도입하였다. 이상의 결과를 정리하 면 다음과 같다.

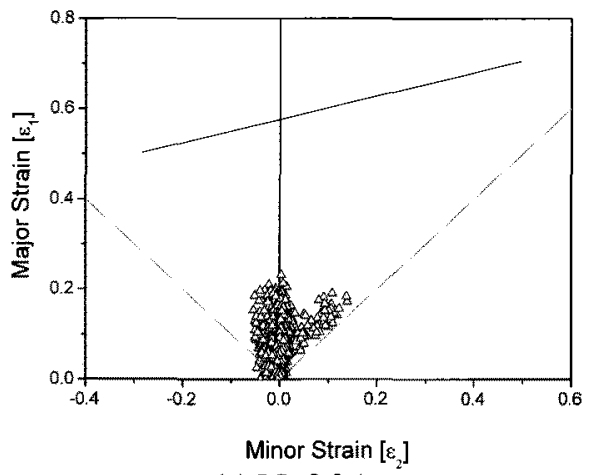

(a) Model A

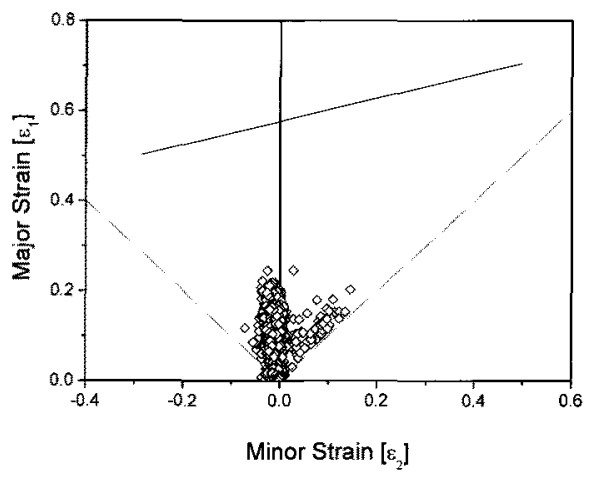

(b) Model B

Fig.16 Failure prediction: crack occurrence $\left(T=250^{\circ} \mathrm{C}\right.$, Feeding depth per cycle $=0.2 \mathrm{~mm}$, Inclination angle $=45^{\circ}$ )

(1) 국부가열장치를 도입함으로써 공구경로가 복잡한 점진 성형 공정에서 효율적으로 소재를 가열할 수 있도록 함으로써 마그네습 합금의 점 진 성형이 가능하도록 하였다.

(2) 성형온도, 1 회 성형깊이, 기울임 각의 세 가 지 공정변수에 대한 영향을 분석한 결과 기울임 각이 성형의 성공여부를 결정하는 가장 주요한 인자인 것으로 나타났다.

(3) 변형률 기반의 고온 성형한계도를 이용하여 성형성을 예측한 결과, 실험과 잘 일치하는 경향 을 보임으로써, 점진 성형 공정에서의 파단기준으 로 적용할 수 있음을 보였다.

\section{참 고 문 헌}

[1] H. Iseki, T. Naganawa, 2002, Vertical wall surface forming of rectangular shell using multistage incremental forming with spherical and cylindrical 
rollers, J. Mater. Process. Technol., Vol.130 131, pp. 675 679.

[2] G. Amgrogio, I. Costantino, L. De Napoli, L. Filice, L. Fratini, M. Muzzupappa, 2004, Influence of some relevant process parameters on the dimensional accuracy in incremental investigation, $\mathrm{J}$. Mater. Process. Technol., Vol.153 154, pp. 501 507.

[3] H. Iseki, 2001, An approximate deformation analysis and FEM analysis for the incremental bulging of sheet metal using a spherical roller, J.
Mater. Process. Technol., Vol. 111, pp. 150 154.

[4] M. S. Shim, J. J. Park, 2001, The formability of aluminium sheet in incremental forming, J. Mater. Process. Technol., Vol .113, pp. 654 658.

[5] S. Shima, H. Kotera, K. Kamitani, T. Bando, Development of Incremental Deep Drawing Process, Metals and Materials, Vol.4, No.3, pp. 404 407.

[6] K. Dai, Z. R. Wang, Y. Fang, 2000, CNC incremental sheet forming of an axially symmetric specimen and the locus of optimuzation", J. Mater. Process. Tech., Vol.102, pp. 164 167. 